\title{
Effect of Nigella Sativa on Oxidative Stress in Post-Menopausal Females
}

\author{
Shazo Sana 1, Muniza Saeed ${ }^{2}$, Hafiz Muhammad Umair ${ }^{3}$ \\ 1 Demonstrator, Department of Physiology, Fatima Jinnah Medical University, Lahore \\ 2 Professor/Head, Department of Physiology, Postgraduate Medical Institute, Lahore \\ ${ }^{3}$ Senior Demonstrator, Department of Hematology, Fatima Jinnah Medical University, Lahore
}

\section{ABSTRACT}

Background: The permanent cessation of menstrual periods in menopause causes a decline in estrogen levels and increased oxidative stress. Both of these factors lead to menopausal symptoms, cardiovascular diseases and osteoporosis in the postmenopausal females that negatively affect the quality of their lives. Antioxidant properties of Nigella sativa are due to its natural ingredient "thymoquinone" and have been studied in various animal and human studies. This study was done to determine beneficial effect of nigella sativa.

Material and Methods: Thirty postmenopausal females were recruited in the study after taking consent. Nigella sativa was administered at a dose of $1 \mathrm{~g} /$ day for 2 months after breakfast. Blood sample was taken for pre and post treatment glutathione (GSH) estimation. The SPSS version 21 was used to analyze the data. Paired $t$ - test was applied. $P$ value of $<0.05$ was considered significant.

Results: Regarding the effect of the Nigella sativa on oxidative stress, result indicated a highly significant increase from baseline $(p<0.0001)$ after 8 weeks' consumption of Nigella sativa. The effect size was calculated both for biochemical parameter GSH and general parameter like weight and BMI. The result of the effect size calculation showed larger effect size for GSH levels (3.9) and moderate sized effect for weight and BMI.

Conclusion: Nigella Sativa showed beneficial antioxidant effects in post-menopausal females and might be responsible for a better quality of life in these women.

Key words: Nigella sativa, Menopause, Oxidative stress

\begin{tabular}{lll}
\hline $\begin{array}{l}\text { Authors' Contribution: } \\
1,2 \text { Conception, synthesis, planning of }\end{array}$ & Correspondence: & Article info: \\
research and manuscript writing & Shazo Sana & Received: January 8, 2019 \\
$\begin{array}{l}\text { Interpretation, discussion, }{ }^{3} \text { Active } \\
\text { participations in data collection }\end{array}$ & Accepted: April 19, 2019 \\
Data analysis. & & \\
\hline $\begin{array}{l}\text { Cite this article. Sana S, Saeed M, Umair HM. Effect of Nigella Sativa on oxidative stress in } \\
\text { post-menopausal females. J Islamabad Med Dental Coll.2019; 8(2):88-91 }\end{array}$ & Funding Source: PGMI Lahore \\
\hline
\end{tabular}

\section{Introduction}

Menopause is characterized by end of menstrual cycles in the absence of any pathological or physiological cause for at least 12 consecutive months. Ovarian functions gradually decline as the females' approach menopause resulting in decreased concentration of both estrogen and progesterone. $^{1}$

The aging process involves increased oxidative stress that is caused by an imbalance between production of oxidants and their elimination by antioxidants. ${ }^{2}$ Oxidative stress increases in postmenopausal females. ${ }^{3}$ This is because of decreasing levels of estrogens as it acts as direct scavenger of free radicals. ${ }^{4}$ The increased oxidative stress in postmenopausal females results in heart diseases, vasomotor disturbances and osteoporosis. ${ }^{5}$

At present, medicinal plants are used for treatment and prevention of many diseases due to easy availability, affordability and safety .6 Among different medicinal herbs, Nigella sativa (Kalonji) is one miraculous herb 
having historical and religious background. ${ }^{7}$ There has been extensive research on the biological qualities and therapeutic properties of Nigella sativa like use as antidiabetic, anticancer, antimicrobial, antipyretic, antiinflammatory and as analgesic. ${ }^{7}$ In addition to all these properties, Nigella sativa has remarkable antioxidant properties. $^{8}$ Thymoquinone (TQ) is the main active component of Nigella sativa that has been found to scavenge all the reactive oxygen species (ROS). ${ }^{9}$ An animal study showed the antioxidant property of $T Q$ as it protected the liver against oxidative stress caused by hepatic carcinogens. ${ }^{10}$ Another study also showed significant reduction in cerebral oxidative stress by using $\mathrm{TQ}$ in rats. ${ }^{11}$ Likewise, $\mathrm{TQ}$ increased the antioxidant enzymes significantly in animal model of colonic carcinogenesis proving excellent antioxidant properties. ${ }^{12}$ Thus in short, menopause results in increased oxidative stress. By administering Nigella sativa can have beneficial effects for postmenopausal women by decreasing oxidative stress.

\section{Material and Methods}

This non-randomized clinical trial was conducted at This interventional study was conducted at Post Graduate Medical Institute, Lahore. From Feb. 2017 - April, 2017. Ethical approval was taken from Ethical Review Board of Post Graduate Medical Institute (PGMI), Lahore. A total of 30 post-menopausal females were inducted through non probability purposive sampling. Inclusion criteria was healthy non obese postmenopausal females with age range 45-55 years. Subjects consuming hormonal replacement therapy (HRT), phytoestrogens and antioxidant medications such as vitamin $\mathrm{E}$ and vitamin $\mathrm{C}$ were excluded from study. Good quality Nigella sativa seeds were brought from market and grinded with the help of electric grinder making a fine powder. Empty capsules of $500 \mathrm{mg}$ size were filled completely with powder manually. A total of 60 capsules were placed in each bottle and stored at room temperature.

Written informed consent was taken from every subject. General physical examination was done. Total $5 \mathrm{ml}$ of the blood was taken in the vacutainer for measuring GSH levels before the Nigella sativa supplementation. Serum was extracted by centrifuging the blood at 3000rpm for a period of 20 min. Serum was stored at $-20{ }^{\circ} \mathrm{C}$. Study subjects were advised to take $1 \mathrm{~g}$ of Nigella sativa (2 capsules $500 \mathrm{mg}$ each) for 2 months daily after taking breakfast. ${ }^{14} \mathrm{~A}$ compliance tabulated sheet was provided to every subject and they were asked to write 'yes' after consuming daily dose. This sheet was reviewed after every 15 day follow up visit. After 2 months, blood was again collected for post treatment GSH levels. Serum GSH was measured by GSH ELISA Kit (Glory Science Co.). Absorbance was read at $450 \mathrm{~nm}$. The detection range of the kit was $30-500 \mathrm{ng} /$.

Data was entered and analyzed by SPSS version 21 . The quantitative variables were expressed as mean \pm SD. The pre and post treatment means were compared by paired t-test. $P$ value of $<0.05$ was considered statistically significant. Calculation of effect size was done by Cohen's $\mathrm{d}$ test and interpreted as up to $0.2=$ small sized effect, up to $0.5=$ moderate sized effect, 0.8 or more $=$ large sized effect. ${ }^{15}$

\section{Results}

This study was conducted on 30 postmenopausal females. General characteristics of the study population are presented in Table I. After administration of Nigella sativa for 8 weeks, result showed a significant reduction in body weight $(p=0.012)$ and BMI $(p=0.011)$ (Table II).

\begin{tabular}{|l|c|}
\hline \multicolumn{2}{|c|}{ Table I: General characteristics of the study population } \\
\hline \multicolumn{1}{|c|}{ Parameters } & Mean \pm SD \\
\hline Age (years) & $49.8 \pm 3.26$ \\
\hline Years being post-menopausal & $1.66 \pm 0.84$ \\
\hline Weight $(\mathrm{kg})$ & $59.9 \pm 5.97$ \\
\hline BMl $\left(\mathrm{Kg} / \mathrm{m}^{2}\right)$ & $25.7 \pm 2.14$ \\
\hline Blood pressure $(\mathrm{mmHg})$ & $142.3 \pm 3.4 / 86.7 \pm 5.38$ \\
\hline Pulse rate (beats $/ \mathrm{min})$ & $86 \pm 6.45$ \\
\hline
\end{tabular}

Regarding the effect of the Nigella sativa on oxidative stress, result indicated a highly significant increase from baseline $(p<0.0001)$ after 8 weeks' consumption of Nigella sativa (Figure 1). The effect size was calculated both for biochemical parameter GSH and general parameter like weight and BMI. The result of the effect size calculation showed larger effect size for GSH levels (3.9) and 
moderate sized effect for weight (0.5) and BMI (0.6) as given in Table III.

\begin{tabular}{|l|c|c|c|}
\hline \multicolumn{4}{|c|}{$\begin{array}{c}\text { Table II: Comparison of general parameters of } \\
\text { postmenopausal women before and after consumption of } \\
\text { Nigella sativa for } 8 \text { weeks ( } \mathbf{n = 3 0} \text { ) }\end{array}$} \\
\hline \multicolumn{1}{|c|}{ Parameters } & $\begin{array}{c}\text { Before } \\
\text { treatment } \\
\text { (mean } \pm \text { SD) }\end{array}$ & $\begin{array}{c}\text { After } \\
\text { treatment } \\
\text { (mean } \pm \text { SD) }\end{array}$ & $\begin{array}{c}\text { p- } \\
\text { value }\end{array}$ \\
\hline Weight $(\mathrm{kg})$ & $59.7 \pm 2.67$ & $57.8 \pm 3.42$ & $0.012^{*}$ \\
\hline BMl $\left(\mathrm{Kg} / \mathrm{m}^{2}\right)$ & $25.5 \pm 2.04$ & $23.6 \pm 6.44$ & $0.011^{*}$ \\
\hline Systolic BP mmHg & $142.6 \pm 5.34$ & $139.2 \pm 2.89$ & 0.063 \\
\hline Diastolic BP mmHg & $88.7 \pm 10.38$ & $84.4 \pm 6.73$ & 0.074 \\
\hline Pulse rate & $86 \pm 6.45$ & $88 \pm 4.13$ & 0.066 \\
\hline
\end{tabular}

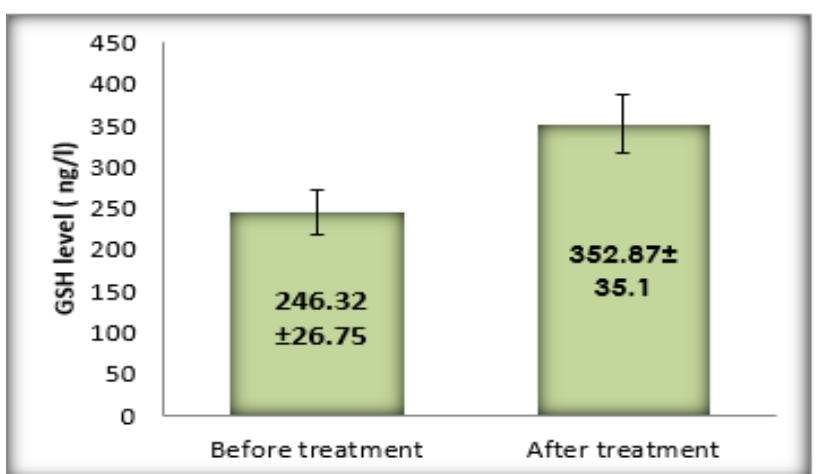

Figure1: Changes in the serum level of GSH after 8-week supplementation of Nigella sativa

\begin{tabular}{|c|c|}
\hline \multicolumn{2}{|c|}{$\begin{array}{l}\text { Table III. Effect size of change in biochemical parameters after } \\
\text { Nigella sativa supplementation }(n=30)\end{array}$} \\
\hline Serum parameters & Effect size \\
\hline GSH & $3.9^{*}$ \\
\hline Weight & $0.5^{\star *}$ \\
\hline BMI & $0.6^{* \star}$ \\
\hline
\end{tabular}

* arge effect size $\quad{ }^{* *}$ moderate effect size

\section{Discussion}

Menopause, a natural phase of reproductive aging is associated with decreased estradiol level and increased oxidative stress which is the main factor causing vasomotor symptoms, osteoporosis and heart diseases. ${ }^{5}$ The current study was conducted to assess whether Nigella sativa supplementation ( $1 \mathrm{~g} /$ day for 8 weeks) reduces oxidative stress in postmenopausal females. The results have shown that Nigella sativa reduced oxidative stress in the study population as shown by significant increase in the serum GSH levels $(P<0.001)$ (Effect size 3.9). This finding suggests that Nigella sativa has anti- oxidant property due to the presence of TQ that trap ROS. Thus, ROS may be less available to convert GSH into its oxidized form resulting in increased GSH levels. Our results are in line with animal study conducted by AlOthman et. al. in 2006. Addition of oxidized corn oil to the rat chow was done in their study to produce oxidative stress; later on, Nigella sativa supplementation greatly reduced oxidative stress indicated by significant increase in tissue GSH levels. ${ }^{16}$

Similarly, Tuluce et.al. (2008) have shown that 6-week supplementation of Nigella sativa in the feed of broiler chicks significantly improved the erythrocyte GSH level and decreased malondialdehyde (MDA) levels as compared to the chicks that were given the normal feed without Nigella sativa supplementation. ${ }^{17}$ Likewise, Mostafa et. al. in 2013 assessed the antioxidative effect of Nigella sativa and garlic. ${ }^{18}$ They administered $3 \mathrm{~g} /$ day of Nigella sativa along with garlic to 30 healthy postmenopausal females for 8 weeks and measured the plasma levels of MDA, superoxide dismutase and glutathione peroxidase before and after supplementation. Their results showed that consumption of $3 \mathrm{~g} /$ day of Nigella sativa along with garlic reduced MDA levels significantly $(P<0.05)$ and increased the levels of superoxide dismutase and glutathione peroxidase significantly $(P<0.05)$. Our findings are similar to this study as GSH improved significantly in our postmenopausal females but our dose ( $1 \mathrm{~g} / \mathrm{day})$ is much lower than used in their study (3g/day).

This dose of $1 \mathrm{~g} /$ day has also been used by Ibrahim et. al. 2014 to prevent metabolic syndrome in postmenopausal females in a randomized control trial. ${ }^{14}$ They administered Nigella sativa for 2 months to 19 and placebo to 18 postmenopausal females with metabolic syndrome. Their results showed that this dose of Nigella sativa was quite effective in reducing body weight, blood glucose level and improving lipid profile. Although Nigella sativa has been well tolerated in subjects of both the studies as well as in our study but it is highly important to take the proper dose of Nigella sativa as Zaghol et. al., 2012 have observed the toxic effects of Nigella sativa on liver and kidney in high doses in rats $\left(15-25 \mathrm{ml}\right.$ of Nigella sativa oil/kg). ${ }^{19} \mathrm{ln}$ addition to decreasing oxidative stress, Nigella sativa also decreased body weight and BMI in the current study. This 
protective effect has also been shown by Shah et. al. 2012 that Nigella sativa reduces body weight and BMI. ${ }^{20}$

Thus, menopause results in increase in oxidative stress and oxidative stress result in menopausal symptoms. Nigella sativa has improved GSH level indicating reduction in the oxidative stress, thus may help in improving in the quality of life of the postmenopausal females. The major limitation of the study was that no control group was included in the study.

\section{Conclusion}

Nigella sativa caused reduction in oxidative stress in postmenopausal females and might be responsible for a better quality of life.

\section{References}

1. Huang $\mathrm{Y}$, Malone $\mathrm{KE}$, Cushing-Haugen $\mathrm{KL}$, Daling JR, Li $\mathrm{Cl}$. Relationship between menopausal symptoms and risk of postmenopausal breast cancer.Cancer Epidemiol Biomarkers Prev.2011;20(2):379-88. doi: 10.1158/10559965

2. Ďurackova Z. Some current insights into oxidative stress.Physiol Res.2010; 59: 459-69.PMID: 19929132

3. Martha ASR, Mariano ZF, Alicia AR, Elsa CM, Victor MN. Menopause as risk factor for oxidative stress.Menopause. 2012;19(3): 361-67.doi: 10.3390/ijms17091388

4. Baltgalvis KA, Greising SM, Warren GL, Lowe DA. Estrogen regulates estrogen receptors and antioxidant gene expression in mouse skeletal muscle, PLoS One. 2010; 5: e10164.doi: 10.1371/journal.pone.0010164

5. Doshi SB, Agrawal A. The role of oxidative stress in menopause. J Mid-life Health. 2013; 4(3): 140-46.doi: 10.4103/0976-7800.118990.

6. Leong XF, Rais Mustafa M, Jaarin K.Nigella sativa and its protective role in oxidative stress and hypertension. Evid based Complement Altern Med. 2013; 2013:120732. doi: 10.1155/2013/120732.

7. Ahmad A1, Husain A, Mujeeb M, Khan SA, Najmi AK, Siddique NA, et. al. A review on therapeutic potential of Nigella sativa: A miracle herb. Asian Pac J Trop Biomed. 2013; 3(5): 337-52.doi: 10.1016/S2221-1691(13)60075-1

8. Yoruk O, Gur FO, Uyanik H, Yasar M, Mutlu V, Altas E, et. al. Anti- oxidant effects of Nigella sativa in the treatment of experimentally induced rhinosinusitis. Maced J Med Sci. 2010;3(2): 132-37. doi:10.3889/MJMS.18575773.2010.0101

9. Mansour MA, Nagi MN, El-Khatib AS, Al-Bekairi AM. Effect of thymaquinone on antioxidant enzyme activities, lipid peroxidation and dt-diaphorase in different tissues of mice: a possible mechanism of action. Cell Biochem Funct. 2002; 20(2): 143-51.doi: 10.1002/cbf.968

10. El- Gendy S, Hessien M, Salam IA, MoradM, Magraby K EL, Ibrahim H.A, et. al. Evaluation of the possible antioxidant effects of Soybean and Nigella sativa during experimental hepatocarcinogenesis by nitrosamine precursors. Turk J Biochem.2007; 32(1): 5-11.

11. Sheikh BY, Mohamadin AM. Thymoquinone a potential therapy for cerebral oxidative stress. AJSC,2012; 1(2): 7692.

12. Harzallah HJ, Grayaa R, Kharoubi W, Maaloul A, Hammami $M$, Mahjoub T. Thymoquinone, the Nigella sativa bioactive compound, prevents circulatory oxidative stress caused by 1,2-Dimethylhydrazine in erythrocyte during colon post initiation carcinogenesis. Oxid Med Cell Longev.2012;2012:854065. doi:10.1155/2012/854065.

13. Kanter M, Coskun O, Korkmaz A, Oter S. 2004. Effects of Nigella sativa on Oxidative Stress and Beta Cell Damage in Streptozocin-Induced Diabetic Rats. Anat Rec A Discov Mol Cell Evol Biol. 2004; 279(1): 685-691.

14. Ibrahim RM, Hamdan NS, Ismail M, Saini SM, Abd Rashid $S N$, Abd Latiff $L$ et. al. Protective Effects of Nigella sativa on metabolic syndrome in menopausal Women. APB. 2014; 4(1): 29-33.doi: 10.5681/apb.2014.005

15. Kirkwood BR, Sterne JAC. Essential Medical Statistics. 2nd ed., London, W.J. Elizebeth; 2002.doi:10.1002/sim.1961

16. Al-Othman AM, Ahmad F, Al-Orfs S, Al-Murshed KS, Arif Z. Effect of Dietary Supplementation of EllataniaCardanum and Nigella sativa on the toxicity of rancid corn oil in Rats. Int J Pharmocol.2006;2(1): 60-5.

17. Tuluce $Y$, Özkol H, Sogut B, Çelik I. Effects of Nigella sativa $\mathrm{L}$. on lipid peroxidation and reduced glutathione levels in erythrocytes of broiler chickens. J Anim Vet Adv.2008;1(3): 95-9.

18. Mostafa RM, Moustafa YM, Mirghani Z, AlKusayer GM, Moustafa KM. Antioxidant effect of garlic (Allium sativum) and black seeds (Nigella sativa) in healthy postmenopausal women. SAGE Open Med.2013; 1: 2050312113517501.doi: 10.1177/2050312113517501.

19. Zaghlola DAA, Kamelb ES, Mohammedc DS, Abbasb NH.The possible toxic effect of different doses of Nigella sativa oil on the histological structure of the liver and renalcortex of adult male albino rats.Egypt J Histol. 2012; 35(1): 127-36. doi: 10.1097/01.EHX.0000411396.11951.02

20. Shah AS, Khan GM, Badshah A, Shah SU et. al.Nigella sativa provides protection against metabolic syndrome. Afr J Biotechnol.2012; 11(48): 10919-25.doi:10.5897/AJB-12890. 